\title{
Architectural form as a subject of cultural communication
}

\author{
$M$. Dymchenko*, N. Brykova, and I. Lokonova \\ Don State Technical University, 344022, Rostov-on-Don, Russia
}

\begin{abstract}
The aim of the article is to investigate the architectural form self-representation processes in the spatial experience of culture. Theoretical and methodological prism of the research is the semiotic concept of architecture of W. Eco and the concept of E. Panofsky correlating with it and explaining the nature of the Gothic architectural form evolution. The architectural reality self-definition problem in the context of the historical development of cultural and anthropological experience spatial codes is considered. On the basis of W. Eco's semiotic concept of architecture we propose the vision of architectural object as a form in which the signifier - the "grammar" of architectural text - is treated as a signifier in the unity of meanings, functions and structures of the work. Architectural form in this capacity is described as a subject of sociocultural communication, an individual link in the spatial code mediation chain of this or that tradition. On the basis of the comparative analysis, we have demonstrated the similarity of semiotic approach to the essence of architecture and Gothic architectural thinking of E. Panofsky. It shows the relevance of this methodology for modern architecture theory allowing to reveal the processes of architectural reality affirmation. The significance of the results for the theory of architecture consists in the fact that the heuristic significance of Eco's semiotic conception of architecture was substantiated by E. Panofsky's conclusions concerning the essence of Gothic form-building. The notion of architectural form as a subject of cultural communication greatly extends the architectural reality affirmative nature notion.
\end{abstract}

\section{Introduction}

Architecture as a system of knowledge cannot go hand in hand with the historical development of reality itself, created by architects in the space of human existence. "Architecture is a project-based art, hence always embedded in the cultural situation" [4, p. 33]. The era of global changes, which has drawn the configurations of man and environment combination into its symbolic "whirlpool", forces us again to search for an answer to the question of how to preserve the architectural look of anthropologically significant space. It is well known, that recent humanitarian thought has produced a number of diagnoses of the general state of culture and man, including the field of spiritual creativity and material creation. They are 'the author's death' or 'social end' and many

\footnotetext{
${ }^{*}$ Corresponding author: kapitel1073@yandex.ru
} 
others. Are such evaluations not applied to architecture? Is architecture not dying? Has the age of architectural creativity come to an end? Doesn't construction destroy architecture today? This almost paradoxical question must be a prologue to the proposed discussion of one of the versions explaining the essence of architecture and architectural thinking that emerged in the second half of the twentieth century. Reflecting upon this very theme, the French postmodernist thinker J. Baudrillard only tries to look for grounds of optimism in diagnosing the metamorphoses of architectural reality: "Wasn't there something in architecture which led to the following state of affairs: all that now occurs in it is based on the disappearance of architecture as - its history, the symbolic configuration of society"? [2, p. 401].

\section{Architecture as a constitutive element of culture: U. Eco's approach}

In order to establish more precisely the possibilities of architectural thinking as an expression of a certain cultural intention, which creates grounds for the claim about architecture as an absolutely affirmative reality, let us turn to Umberto Eco's concept. In the framework of the semiotic approach, he considers the essence of architecture regardless of the construction or engineering technologies and materials development. In our opinion, Umberto Eco has managed to identify those facets of the architectural environment, through which it acquires a quite independent being in the field of cultural formation of man himself. In Eco's conception architecture is regarded as a means of socio-cultural communication, which is not just a means of communication between its subjects, but actualizes and affirms a certain section of reality, constitutes a field of meanings, which do not refer to other - beyond architecture - structures, but fully rely on those forms that assume space itself as a condition of spiritual affirmation and formation of man.

The main question for Eco is whether architecture is a constitutive element of culture. An affirmative answer to this question leads to the fundamental problem of the communicative role of architectural form. The thinker builds the following logical chain of arguments to define it. If all human culture is a totality of signs and meanings, architecture is by no means an exception. Only unlike a simple language or some other sign systems, two kinds of reference (interrelation of the signifier and the signified) can be distinguished in architecture.

The first one is a simple external observation, contemplation, phenomenology (or phenomenon) of this or that image, relying on a psychologized subjective perception, which can distort space, "stretch" it or compress it (it should be reminded that this very perception was the basis for the interpretation of the essence of architectural form in R. Arnheim's concept [10]). The second kind of reference is precisely what is of central interest to U. Eco and to modern architectural theory. The architectural form has an enormous generative potential. It is not just a passive subject of somebody else's telling (referring, transmitting) but also opens up the systems of meanings and notions in its own right. In other words, the first reference has a purely external informative character. The second one, irrespective of who and when "reads" it, contains in itself the rules of its own reading and configuration with other architectural texts. The academician's central thesis is that the architectural form as a historically concrete experience of spatial existence of man and society acts as a communicative subject of culture and its constitutive element.

What is the difference between the architectural sign and other sign systems in culture? In answering this question, Eco stresses that the architectural form does not refer to a material medium or object at all. If this were the case, then the historical need for specific architectural thinking and creativity as a discovery of a completely unique world, a holistic non-reducible experience within a particular tradition would simply be lost. The 
architectural sign, as the representative of structuralist thought of the second half of the last century, French author Roland Barthes wrote, is "a signifier, the signified of which is its own functional function" [1, p. 211]. This signifier is the reality that, relying on the endless variation of geometric forms, creates its own special Text (a socio-anthropological text), which synthesizes sociocultural preconditions and a special "grammar" of conjugation with other architectural texts (forms). As Yu. I. Kurbatov notes, "to a certain extent, the syntax of the architectural form is identical with the term "composition" which, overcoming the laws of gravitation, brings together the elements into a complete harmonised whole" [5, p. 126]. The reference to context is not direct or immediate. The architectural sign denotes and connotes. Both to itself and to neighbouring structural texts, metatexts and other formations (for example, the system of the religious picture of the world). The architectural form is self-dominant. Just as any other artistic form. And it is in this capacity that is the subject of communication.

\section{Architectural form as a subject of communication: morphology and self-reference}

This or that form is a peculiar manifestation into the world of a particular horizon of meaning that is topical for a given situation and community. A simple material carrier, let's say a pure building block, a "scaffolding", a material, cannot communicate. It is always the form that makes symbolic contact. A simple and well-known example is granite. This particularly durable material has been one of the most sought-after materials in construction virtually throughout the entire documented history of civilization. But does the granite itself enter into a communicative relationship with the other structural elements of the facade, the building as a whole, the square or other architectural ensemble? It does not. It is the shape that communicates. If these are huge boulders that form the masonry of the Solovetsky fortress wall in the North of Russia, it is one and quite definite cultural text that broadcasts to the contemplative eye its symbolic information about the specifics of the Orthodox ascetic outlook and way of life of the inhabitants of the Russian North. The same red Finnish granite in the majestic colonnade of St Isaac's Cathedral forms a fundamentally different text. A text that expresses the meanings of the ideocratic state system of the Russian Empire. And there are an enormous number of such examples. It is not the material substrate of the building that communicates, but the morphological structure through which the architectural "body" acquires completely different super-physical properties and parameters.

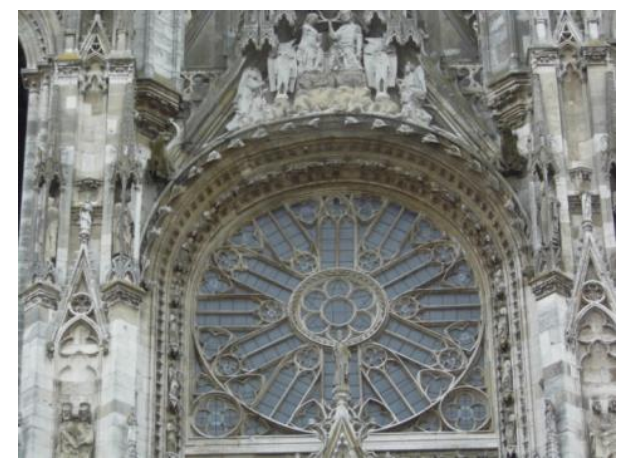

Fig. 1. «The Rose» of Rouen Cathedral as the clearest example of an analytically self-explanatory architectural form. France

At the same time, form cannot be seen as something which is superimposed on "matter" outwardly and then remains once and for all deadly attached to a particular object. 
Architectural projects that tried to realize a single social utopia (which is characteristic of industrial and post-industrial development), are typically dominated by such dead forms that turn out to be closed to their abstracted foundation, incapable of discovering universal cultural codes embodied in architecture. The cultural code, in this case, is the rule of 'reading' the corresponding text as a certain sequence of meanings in any area where there is a relationship between the signifier and the signified.

According to Eco, the architectural form forms a certain outwardly unfolded, i.e., fundamentally open way of broadcasting meanings. As for the results of the search for life form in the context of post-industrial evolution of society, experience shows that geometric minimalism remains the only sufficiently universal text capable of defining cultural codes. A striking symbolic expression of which is the famous "Arch of Brotherhood" or simply La Grande Arche, located in the new district of Paris La Défense, which completes the general compositional axis of the French capital, starting from the Louvre Throne Room and the Little Arch (Carrousel), located in the Tuileries Garden. The theme of the unity of the entire human community in this project by Johan Otto von Spreckelsen is expressed through the minimisation of compositional difference, 'aligning' the arched structure of the spatial place and its 'architectonics'.

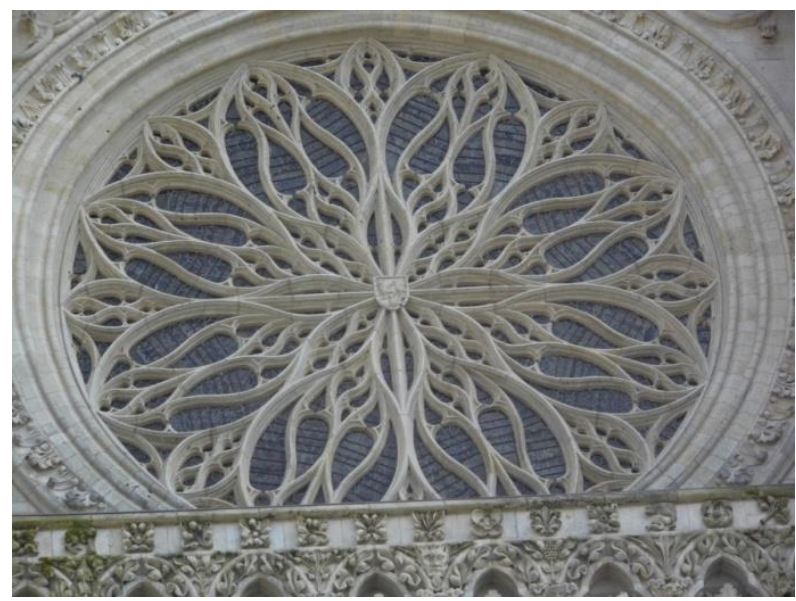

Fig. 2. «The Rose» of Amiens Cathedral. A striing example of a self-affirming architectural form that assumes its own content - immanent tectonics - on the basis of spelling out the tectonics of the constructive. France

Architectural form is not an outer shell of some idea or meaning [8]. And only in this capacity it acts as a conductor or manifestation of the metamaterial code into the world of sensual data (in the spatial structure). In Eco's semiotic conception the architectural form synthetically includes the plane of reference and auto-reference. It is this latter aspect that is the key one. It makes the opposition between external and internal, true and false, contingency, particular and universal, necessary, disappear in the architectural text. Namely: denoting its own meaning, the form or "grammar" of the text communicates to the outer world (the world of subjective phenomenology) not only its material component enclosed in this or that geometrical system, but the meaning itself as it exists in its own authentic form. That is, it is a subject of its own telling, describing, dialoguing with other worlds (codes). The text of the form or its "syntax" and "semantics" refers to the very principle of its own creation according to one or another dominant or simply chosen code. Eco distinguishes the following types of codes: "1. Syntactic codes: Characteristic in this sense is the code referring to the technique of construction... 2. Semantic codes a) the articulation of architectural elements 1) elements signifying primary functions: roof, 
balcony, dome, staircase, window... 2) elements which stand for secondary 'symbolic' functions: metope, pediment, column, tympanum... 3) elements denoting functional purpose and co-meaning the "ideology of living": salon, part of the dwelling where day is spent, night is spent, living room, dining room, ... b) articulation by type of structure 1) social: hospital, country house, school, castle, palace, station... 2) spatial: temple on a circular base, with a base in the form of a Greek cross, "open" plan, labyrinth..." [9, p. 294-295]. All the above-listed codes in themselves are external to the architecture. But since the architectural form is autoreferential and not only subject to external contemplation, it is structured in such a way that dialogue for it acts as a moment of self-determination and identity. We can, for example, still "read" the architectural codes of the Gothic today. Despite the fact that the dominant picture of the world in which the creators of Reims or Amiens Cathedral worked has long lost relevance for the professional community of architects. It has survived only as a fact of the Christian culture and philosophy history. As Eco underlines, describing the informativity of architectural form as a communicative subject, "signifying itself, it at the same time informs not only about the functions it signifies and carries out, but also about the way in which it intends to denote and carry them out" [9, p. 302]. And the phenomenon of the so-called modern 'electronic baroque' illustrates the focus on the 'play' of form itself, irrespective of the material in general, which is characteristic of the post-industrial stage of architectural development. "The new deconstructivity baroque also demonstrates, in principle, a certain ambivalence which does not allow us to say unequivocally whether we are looking at an architectural body or a mirage. Its genesis is ambivalent. On the one hand it is an organo-morphic form, which tries to bring into architecture the laws of the natural landscape construction, the movement of sand, earth, water and so on. On the other hand, the form is born out of those virtual "whirlwinds" that enable the construction of three-dimensional objects in computer programmes - and in this sense the form is not so much organo-morphic as cyber-morphic" [7].

\section{Architectural Form as a Symbol: E. Panofsky's Concept.}

In our opinion, this approach to the essence of architecture, realized at the level of explaining the text of architectural form as a conjunction of signs, notions and meanings, allows us to speak about the presence in this field cultural-anthropological and social experience spatial-plastic code autonomous evolution objective bases' human. It should be noted that this approach correlates with the ideas of Ervin Panofsky, a German scholar of the first half of the 20th century, and specifically with the model of Gothic architectural thinking developed by him (in this case Panofsky himself first of all relies on E. Cassirer's conception of culture symbolic forms).

The thing is that Panofsky, using a rich material of "high" Gothic architecture monuments of the famous cathedrals in France, created from the end of XII to the beginning of XIV century, convincingly proves that this architectural form in its development went beyond the limits of ancient order "monologue", creating a completely unique (scholastic) text-dialog. Its structure only tells us how it was created, how it was built. The structure "narrates" the universal principle of overcoming the "earthly gravitation" of the construction, the "easing" of the stone body architectural mass, the removal of the construction tectonism precisely by locking the grammar of the construction onto its own foundation. "E. Panofsky also noted the "correspondence of form to symbolic meanings", for which he used the term "artistic intention". As levels of iconological analysis, Panofsky distinguished primary or natural content, including actual and expressive content (constituting the 'domain of artistic motifs'), secondary or conventional content 
(constituting the domain of images, plots and allegories) and inner meaning (the domain of 'symbolic meanings')" [4].

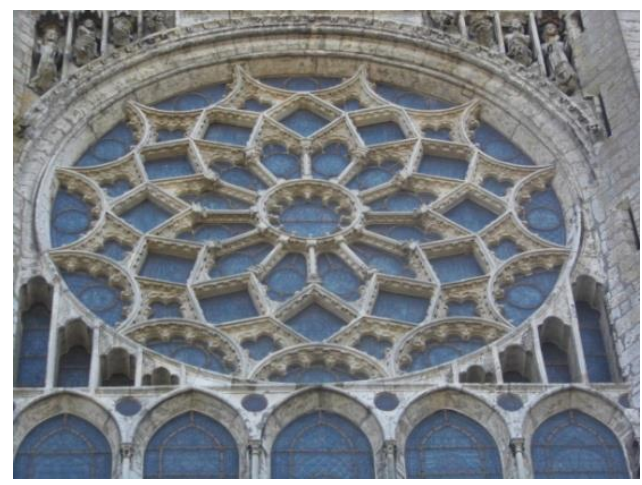

Fig. 3. «The Rose» of Chartres Cathedral. France

The Gothic architectural form - and this is the root of its peculiar aesthetic - was for the first time in the history of architecture the basis of the affirmative of architectural reality, thanks to the fact that the only subject of its broadcasting was the form itself, the text as an isolated universalized 'rule' of construction. In other words, the content of such "syntactic" formatting of architectural construction was the form itself or a stone "narrative" (it is in this that Panofsky sees the underlying reason for the use of the system of arc-boutant and buttresses in the Gothic). As the scholar points out, 'A man imbued with a scholastic mindset would consider the form of organisation of architecture - as well as the form of organisation of literature - from the point of view of "manifestation". He would also take for granted that the primary task of the multitude of elements of which the cathedral is composed is to ensure stability... However, he would not have been satisfied if the disintegration of the building did not allow him to experience again the very process of the construction of the architecture... The rich variety of columns, nervures, buttresses, openwork carvings, pinnacles and floral decorative elements was to him a self-analysis and self-explanation of architecture, just as the traditional apparatus of parts, sections, paragraphs and clauses was a self-analysis and self-explanation of the mind. He was just as much in favour of the unconditional clarification of function by means of the unconditional clarification form thought by means of language" [6, pp. 270-272].

To sum up briefly, we shall note that consideration of architectural form as a subject of cultural and social communication, on which Umberto Eco insists, acquires one of the brightest and strongest historical arguments in the case of Panofsky's analysis of the Gothic universe (in spite of general methodological differences and conceptual horizons covering different scientific and philosophical schools of the 20th century).

The main conclusion can be briefly formulated as follows: if the science of architecture (like the "science of literature" which, for example, R. Barth wrote about [1, pp. 375-382]) pretends to be the knowledge of architecture having universality and not depending on the development, for example, of engineering, the construction technologies and methods of mathematical modeling, design etc., then architectural reality must be considered as a spatial expression of the code of cultural and anthropological experience (on the level of deep mediation of an individual). The architecture science methodology cannot be distanced from the subject itself. 


\section{Conclusion}

Architectural form (and architecture in general through it) is a subject of socio-cultural communication, as each architectural work (cathedral, palace, square or another architectural ensemble) individualizes one or another semantic code (for example, related to religion or, as today, to market development, global outlook), which acquires its unique voice, entering into a dialogue with similar other formations through the appropriate spatial structure, "grammar" and "syntax". From this point of view, the semiotic concept of architecture essence proposed by the Italian author Umberto Eco is highly relevant and in demand for the contemporary architectural studies' development and has an enormous and still uncovered heuristic value for understanding the deep foundations of the dialogue between different cultural and historical traditions and civilizational lines expressed in the architectural creativity.

The results of the architectural form study as a subject of cultural communication can qualitatively expand theoretical ideas about the unity of historical and methodological aspects of the evolution of the principles of architectural forms and architectural thinking itself.

\section{References}

1. R. Bart, Selected works: Semiotics: Poetics (Progress, Moscow, 1989)

2. J. Baudrillard, M.B. Wilkowski, The Architecture: truth or radicalism? Architecture sociology (Fund «Russkij Avangard», M., 2010)

3. V.G. Vlasov, Arkhitekton: Bulletin of Higher educational Institutions 3 (59), (2017) http://archvuz.ru/2017_3/1 (Access date: 20.02.2018).

4. I.A. Dobritsyna, Academia. Architecture and Construction 4, 33-39 (2016)

5. Yu.I. Kurbatov, Essays on the theory of shaping: a course of lectures (SPSACE, SPb., 2015)

6. E. Panofsky, Gothic architecture and scholasticism, Panofsky, E. Perspective as «symbolic form». Gothic architecture and scholasticism (Azbuka-Klassika, SPb., 2004)

7. G. Revzin, Baroque without metaphysics (Vyzov - Otvet. 2008) http://www.projectclassica.ru/v_o/23_2008/23_2008_o_01.htm (Access date: 21.02.2018).

8. Sh. Shukurov, From the iconography of architecture to generate architectural form, Architecture and social world of a human (Progress-Traditsiya, M., 2012)

9. U. Eco, Absent structure. Introduction to semiology (Symposium, SPb., 2004)

10. R. Arnheim, Art and Visual Perception: A Psychology of the Creative Eye. New version (University of California Press, Berkeley and Los Angeles, 1974) 